\title{
Influence of moderate alcohol consumption on obstructive sleep apnoea with and without AutoSet “ nasal CPAP therapy
}

\author{
H. Teschler*, M. Berthon-Jones**, T. Wessendorf*, H-J. Meyer*, N. Konietzko*
}

\begin{abstract}
Influence of moderate alcohol consumption on obstructive sleep apnoea with and without AutoSet ${ }^{\mathrm{TM}}$ nasal CPAP therapy. H. Teschler, M. Berthon-Jones, T. Wessendorf, HJ. Meyer, N. Konietzko. @ ERS Journals Ltd 1996.

ABSTRACT: Snoring worsens with high alcohol consumption. It is unclear whether moderate alcohol intake worsens sleep and breathing in subjects with obstructive sleep apnoea syndrome (OSAS), and whether alcohol increases the pressure requirement for nasal continuous positive airway pressure (CPAP).

Fourteen adult males with untreated OSAS but without heart or lung disease were studied (age $53 \pm 9$ yrs, body mass index (BMI) $33 \pm 5 \mathrm{~kg} \cdot \mathrm{m}^{-2}$ (mean \pm SD). The subjects underwent overnight polysomnography on four occasions: control, alcohol, CPAP, and alcohol + CPAP. On the alcohol nights, the subjects drank $1.5 \mathrm{~mL} \cdot \mathrm{kg}^{-1}$ body weight (BW) vodka (40\% alcohol by volume) (blood alcohol with and without CPAP $0.45 \pm 0.1$ and $0.47 \pm 0.2 \mathrm{mg} \cdot \mathrm{mL}^{-1}($ mean $\left.\pm \mathrm{SD})\right)$. On the CPAP nights, the pressure required to prevent apnoea, snoring, and silent inspiratory airflow limitation was determined using an autotitrating nasal CPAP system (ResCare AutoSet ${ }^{\mathrm{TM}}$ ). Alcohol and control nights were performed in random order.

Without CPAP, alcohol produced a small non-significant decrease in the percentage of rapid eye movement (REM) sleep (control 11 $\pm 2 v s$ alcohol 8 $\pm 1 \%$ (mean \pm SEM)), but with CPAP there was no such effect (control $15 \pm 2$ vs $17 \pm 2 \%$; CPAP $\times$ alcohol interaction $p=0.015)$. With CPAP, slow-wave sleep in the first $2 \mathrm{~h}$ increased slightly with alcohol (control 39 $\pm 6 v s$ alcohol $51 \pm 4 \% ; \mathrm{p}=0.004)$. Arousal index without CPAP increased slightly with alcohol (control $43 \pm 5 \mathrm{vs}$ alcohol $49 \pm 6$ events $^{-1} \mathrm{~h}^{-1} ; \mathrm{p}=0.02$ ). There was little or no effect of alcohol on other sleep stages, arousal index, apnoea index, apnoea/hypopnoea index, mean or longest event duration, mean or worst arterial oxygen saturation, with or without CPAP, either for the full night or for the first $2 \mathrm{~h}$. There was no change in the pressure requirement for CPAP (full night: control $11.9 \pm 0.9 v s$ alcohol $12.5 \pm 0.9 \mathrm{cmH}_{2} \mathrm{O}$; first $2 \mathrm{~h}$ : $10.9 \pm 0.6 v s 11.1 \pm 0.8 \mathrm{cmH}_{2} \mathrm{O}$ ).

Moderate alcohol intake (in the form of vodka) has little effect on breathing or saturation during sleep in subjects with mild-to-severe obstructive sleep apnoea, and no effect on the pressure required for continuous positive airway pressure in order to prevent apnoea, snoring, and flow limitation. These results cannot be extrapolated to other doses or forms of alcohol, or to subjects with concurrent heart or lung disease.
\end{abstract}

Eur Respir J., 1996, 9, 2371-2377.

The effects of alcohol consumption upon sleep-related abnormalities of respiration are not entirely clear. The results of various studies suggest that sleep is worsened in snorers, but the results are less clear in subjects with obstructive sleep apnoea (OSAS) syndrome [1-7].

Alcohol consumption worsens snoring [1] and impairs upper airway patency [3-7]. In normals and nonapnoeic snorers, little worsening of breathing during sleep occurs with alcohol doses up to $1 \mathrm{mg} \cdot \mathrm{kg}^{-1}$ body weight (BW) [8-10], but deterioration is seen at higher doses. Alcohol consumption of $2 \mathrm{mg} \cdot \mathrm{kg}^{-1} \mathrm{BW}$ increased the apnoea/ hypopnoea index (AHI) from 0.3 to 0.9 events $\cdot \mathrm{h}^{-1}$, the minimum arterial oxygen saturation fell from 93 to $88 \%$, and the longest desaturation rose from 4 to $26 \mathrm{~s}$ with alcohol [11]. In another study, $2 \mathrm{mg} \cdot \mathrm{kg}^{-1} \mathrm{BW}$ vodka increased AHI from 3.8 to 7.5 events.h-1 but with negligible desaturation [12].

\begin{abstract}
*Dept of Pneumology, Ruhrlandklinik, Medical Faculty, University of Essen, Essen, Germany, **ResMed Ltd, North Rhyde, Sydney, Australia.
\end{abstract}

\author{
Correspondence: H. Teschler \\ Ruhrlandklinik \\ Tüschener Weg 40 \\ D-45239 Essen \\ Germany \\ Keywords: Alcohol \\ AutoSet TM \\ continuous positive airway pressure \\ obstructive sleep apnoea
}

Received: November 91995

Accepted after revision June 41996
In subjects with OSAS, alcohol modestly worsens breathing during sleep. Collop [13] found that alcohol 0.5 $\mathrm{mg} \cdot \mathrm{kg}^{-1} \mathrm{BW}$ doubled the AHI from 9.6 to 20.2 events $\cdot \mathrm{h}^{-1}$, and nadir saturation fell from 85 to $79 \%$. In subjects with more severe OSAS, SCRIMA et al. [8] reported an increase in the number of hypoxic episodes from a mean of 134 to 210 episodes.night ${ }^{-1}$ with $3 \mathrm{oz}$ of $80 \%$ proof spirit (approximately $\left.0.5 \mathrm{~g} \cdot \mathrm{kg}^{-1} \mathrm{BW}\right)$. Severe desaturations $(<89 \%)$ increased from 39 to 114 per night, with most events occurring during the first $160 \mathrm{~min}$. Guilleminault and RoseKIND [14] reported an increase in AHI from 23 to 29 in four subjects after $300 \mathrm{~mL}$ of bourbon (approximately $1 \mathrm{~g} \cdot \mathrm{kg}^{-1} \mathrm{BW}$ ). Mean lowest saturation fell from 83 to $74 \%$ in non-rapid eye movement (NREM) sleep and 74 to $71 \%$ in REM sleep. VALET et al. [15] reported no change in the apnoea index with a blood alcohol concentration of $1.25 \mathrm{~g} \cdot \mathrm{kg}^{-1} \mathrm{BW}$, but the duration of the 
longest apnoea increased by a median value of $50 \%$ of control.

Heavier alcohol consumption is related to more severe effects on sleep. Issa and Sullivan [1] studied heavier social drinkers. Subjects drank wine or beer in an amount equal to their maximum social intake. (Typical intake was given as 200-300 g alcohol per week (about 1.3-2.0 $\mathrm{g} \cdot \mathrm{kg}^{-1} \mathrm{BW}$ per night over a weekend). Alcohol produced a dramatic worsening in sleep-disordered breathing and oxygenation in all subjects, largely confined to the first $2 \mathrm{~h}$ of the night.

Potentially, alcohol consumption might be expected to change the continuous positive airway pressure (CPAP) requirements for the treatment of OSAS [2, 12, 16]. MitLER et al. [12] showed that $2 \mathrm{~mL} \cdot \mathrm{kg}^{-1} \mathrm{BW}$ vodka produced a significant increase in the pressure required for CPAP from 4.8 to $6.2 \mathrm{cmH}_{2} \mathrm{O}$. However, when BERRY et al. [16] tested 10 obese males with OSAS with nasal CPAP titration, there was no important change in the AHI (3.6 \pm 3.7 episodes $\cdot h^{-1}$ without ethanol, $1.9 \pm 2.7$ episodes $\cdot \mathrm{h}^{-1}$ with ethanol $0.75-1.0 \mathrm{~mL} \cdot \mathrm{kg}^{-1} \mathrm{BW}$ ), and there were no changes in the number or severity of desaturations.

The aim of the present study was to determine whether: 1) moderate alcohol consumption (vodka $1.5 \mathrm{~mL} \cdot \mathrm{kg}^{-1} \mathrm{BW}$ $=0.5 \mathrm{~g} \cdot \mathrm{kg}^{-1} \mathrm{BW}$ ) exacerbated sleep-disordered breathing in subjects with mild-to-severe untreated obstructive sleep apnoea syndrome without co-existing lung disease; and 2) whether this dose of alcohol increased the pressure required for nasal CPAP in order to prevent apnoeas, hypopnoeas, and silent inspiratory airflow limitation in these subjects, as determined by the AutoSet ${ }^{\mathrm{TM}}$ selfadjusting nasal CPAP system.

\section{Methods}

\section{Subjects}

The study population consisted of 14 consecutively recruited men with OSAS confirmed at a diagnostic allnight sleep study. Age ranged 36-66 yrs (mean 53 \pm 9 yrs $\mathrm{SD})$. Body mass index (BMI) ranged $25.4-42.9 \mathrm{~kg} \cdot \mathrm{m}^{-2}$ $\left(33 \pm 5 \mathrm{~kg} \cdot \mathrm{m}^{-2}\right)$. All of the subjects were regular social drinkers. Their consumption ranged from one to three bottles of wine (equivalent to $225-675 \mathrm{~mL}$ of $40 \%$ vod$\mathrm{ka})$ or 3-10 bottles of beer (equivalent to $188-625 \mathrm{~mL}$ of $40 \%$ vodka) a week. The liver function studies, creatinine, and urea were normal for all subjects. Patients with a history of hepatitis or diabetes mellitus were excluded. No subject had signs or symptoms of nasal deformity, allergic rhinitis or upper airway infection. Subjects with daytime respiratory failure or nocturnal myoclonus ( $>5$ spasms $\cdot h^{-1}$ ) were excluded, and spirometry and chest radiograph were normal in all subjects. The project was approved by the institutional review board of the University of Essen, and informed consent was obtained from each participating subject.

\section{Study design}

Each subject underwent four consecutive nights of full polysomnography. During the first two nights, the subjects did not receive CPAP but were given alcohol in random order. During the third and fourth nights, the subjects were treated with CPAP and alcohol in a randomized fashion. On the untreated nights, the subject slept without CPAP. On the CPAP nights, the subject slept with an automatic, self-adjusting computerized nasal CPAP system (AutoSet ${ }^{\mathrm{TM}}$, ResMed, North Ryde, NSW, Australia). On the alcohol nights, the subject drank vodka (40\% ethanol) $1.5 \mathrm{~mL} \cdot \mathrm{kg}^{-1}\left(=0.5 \mathrm{~g} \cdot \mathrm{kg}^{-1}\right) \mathrm{BW}$ $1 \mathrm{~h}$ prior to lights-out. Blood alcohol level was measured in all subjects at bedtime. Subjects reported taking no other alcohol in the $24 \mathrm{~h}$ prior to any of the four nights, and no alcohol was found during the control nights in any subject.

\section{Self-setting device}

The AutoSet ${ }^{\mathrm{TM}}$ nasal CPAP system [17, 18] measures mask airflow with a pneumotachograph. The flow signal is further processed to obtain instantaneous leak, respiratory airflow and snore. Pressure is initially set to 4 $\mathrm{cmH}_{2} \mathrm{O}$. The device increases pressure in response to apnoeas greater than $10 \mathrm{~s}$, snoring, and changes in the inspiratory flow-time curve suggestive of inspiratory airflow limitation. A maximum pressure limit of $20 \mathrm{cmH}_{2} \mathrm{O}$ is provided.

Inspiratory airflow limitation. If the airway is acting as a floppy tube (Starling resistor), mid-inspiratory airflow will be independent of effort. The software normalizes the duration and amplitude of the inspiratory flow-time curve, and looks for flattening over the middle $50 \%$ of inspiratory time. The software very slowly increases the pressure if the degree of mid-inspiratory flattening exceeds that occurring $50 \%$ of the time in a control group of 16 healthy sleeping normals. This is the principle method of adjusting the pressure.

Snoring. Snoring is estimated semiquantitatively from the $30-300 \mathrm{~Hz}$ bandpassed audio components of the inspiratory airflow signal. The presence of snoring produces a rapid increase in pressure. This is rare, because the flow limitation algorithm acts pre-emptively to increase the pressure prior to the onset of snoring.

Apnoeas. Not all apnoeas involve closure of the airway. During an apnoea, the device modulates mask pressure at low amplitude and high frequency, measures the resultant induced airflow, and estimates the conductance. If the estimated conductance is above a threshold, the CPAP pressure is taken as inadequate and the pressure is increased. This is also rare, because the flow limitation and snoring algorithms have in general set an adequate pressure in advance. If there are no further abnormalities detected, the pressure decreases towards $4 \mathrm{cmH}_{2} \mathrm{O}$ with a time constant of $20 \mathrm{~min}$ for snore and flow limitation, and $40 \mathrm{~min}$ for apnoeas. The recommended pressure is calculated (as per the manufacturer's instructions) as the 95th centile pressure encountered for mask-on periods in which the measured leak is less than $0.4 \mathrm{~L} \cdot \mathrm{s}^{-1}$ [19]. The "median pressure" is calculated as the time-weighted median of CPAP delivered to the subject during the treatment time. 


\section{Sleep studies}

Nocturnal polysomnography was commenced at the patient's usual bedtime and terminated after final waking or at 06:00 h. Standard polysomnography was performed using the Madaus ED24 sleep recorder (Madaus, München, Germany). Paper speed was $10 \mathrm{~mm} \cdot \mathrm{s}^{-1}$. Surface electroencephalography (EEG) (C3-A2 and C3-O1), submental electromyography (EMG), and left and right electro-oculography (EOG) were used to stage sleep according to RECHTSCHAFFEN and KALES [20]. Anterior tibial EMG was recorded to screen for periodic leg movements. Ear oximetry (Biox III; Bioximetry Technology, Boulder, CO, USA) was used to record arterial oxyhaemoglobin saturation $\left(S \mathrm{a}, \mathrm{O}_{2}\right)$. Desaturations were defined as a fall in the $\mathrm{Sa}, \mathrm{O}_{2}$ of $>4 \%$. Mean nadir saturation was calculated. Oronasal airflow was monitored with a thermistor, and respiratory effort and pattern were monitored with thoracic and abdominal stain gauges. In addition, on the two CPAP nights, the quantitative nasal airflow signal from the AutoSet ${ }^{\mathrm{TM}}$ pneumotachograph was recorded.

Polysomnograms were scored by Ruhrlandklinik sleep unit staff blinded to the study design for disordered breathing episodes and for changes in $\mathrm{Sa}_{\mathrm{a}} \mathrm{O}_{2}$ using the following criteria: obstructive apnoeas were identified as episodes of cessation of airflow lasting more than $10 \mathrm{~s}$ and associated with paradoxical movements of the chest wall and abdomen; hypopnoeas were defined as episodes other than apnoeas lasting more than $10 \mathrm{~s}$ during which the thermistor signal (untreated nights) or nasal airflow signal (CPAP nights) was reduced to less than $50 \%$ of its magnitude during normal unobstructed breathing and $\mathrm{Sa}_{\mathrm{a}} \mathrm{O}_{2}$ dropped by at least $4 \%$. The apnoea index and obstructive apnoea index were calculated as the number of apnoeas and obstructive apnoeas, respectively, per hour of sleep. The AHI was calculated as the number of apnoeas and hypopnoeas per hour of sleep. The total arousal index was defined as the number of abrupt changes of sleep stage associated with a change in the EEG, such as increased alpha activity per hour. All the above indices were calculated separately for: 1) the first $2 \mathrm{~h}$ of sleep; and 2) the entire sleep period.

\section{Statistical analysis}

All values are given as mean \pm SEM unless otherwise stated. The effect of alcohol on each parameter was tested separately with and without CPAP, using paired ttests on the rank transformed data. This approach was in general preferred to using a two-factor repeated measures analysis of variance (ANOVA), using CPAP as one factor and alcohol as the other, because the effects of CPAP were so large. However, to test whether the effect of alcohol was different with and without CPAP, a two-factor repeated measures ANOVA on the ranktransformed data was performed, and the CPAP by alcohol interaction tested. The correlation between untreated control AHI and the difference between prescribed pressure from control to alcohol night was calculated, to test the hypothesis that the change in pressure requirement was different for subjects with low and high untreated AHIs. A separate repeated measures ANOVA was performed to determine whether the order of presentation of control and alcohol nights influenced AHI or percentage of REM sleep. Statistical significance was taken as a p-value of less than 0.05 .

\section{Results}

The blood alcohol level immediately before sleep on the alcohol night without CPAP was $0.47 \pm 0.2 \mathrm{mg} \cdot \mathrm{mL}^{-1}$ (mean $\pm \mathrm{SD}$ ), and on the alcohol + CPAP night was $0.45 \pm$ $0.1 \mathrm{mg} \cdot \mathrm{mL}^{-1}$.

\section{Effect of alcohol on sleep and breathing without CPAP}

Results are summarized in table 1 and figure 1 . Without CPAP, alcohol produced a small increase in the arousal index for the whole night. Otherwise, there was no important or statistically significant change in the apnoea index (AI), AHI (fig. 1a), mean event duration, longest event duration, mean nadir $\mathrm{Sa}_{\mathrm{a}} \mathrm{O}_{2}$, or worst $\mathrm{Sa}_{\mathrm{a}} \mathrm{O}_{2}$ (table 1). This was true both for the first $2 \mathrm{~h}$ and for the entire night and both mean and median values. In one subject, the longest hypopnoea without CPAP increased from 66 $\mathrm{s}$ without alcohol to $180 \mathrm{~s}$ with alcohol; however, the subject maintained some ventilation during this long event. The worst reduction in $\mathrm{Sa}_{\mathrm{a}} \mathrm{O}_{2}$ with alcohol (to 80\%) was actually less severe than the worst without alcohol (to $73 \%$ ).

In many subjects, the amount of REM sleep (table 1) expressed as a percentage of time in bed (TIB), decreased sharply with alcohol, but this was not a consistent

Table 1. - Respiratory, sleep stage and arousal results for the first $2 \mathrm{~h}$ and for the whole diagnostic night without (control) and with alcohol, without the use of CPAP

\begin{tabular}{|c|c|c|c|c|}
\hline & \multicolumn{2}{|c|}{ First $2 \mathrm{~h}$} & \multicolumn{2}{|c|}{ Whole night } \\
\hline & Control & Alcohol & Control & Alcohol \\
\hline AHI events.h $\mathrm{h}^{-1}$ & $\begin{array}{l}45.6 \pm 6.2 \\
(45.3)\end{array}$ & $\begin{array}{c}41.0 \pm 7.8 \\
(46.3)\end{array}$ & $\begin{array}{l}44.1 \pm 7.2 \\
(39.4)\end{array}$ & $\begin{array}{c}50.6 \pm 8.0 \\
(55.2)\end{array}$ \\
\hline AI events $\cdot \mathrm{h}^{-1}$ & $\begin{array}{c}16.7 \pm 6.8 \\
(3.3)\end{array}$ & $\begin{array}{c}14.7 \pm 5.6 \\
(3.5)\end{array}$ & $\begin{array}{c}20.3 \pm 6.9 \\
(7.6)\end{array}$ & $\begin{array}{c}23.8 \pm 7.3 \\
(10.8)\end{array}$ \\
\hline Event duration $\mathrm{s}$ & $\begin{array}{c}23.0 \pm 2.1 \\
(21.3)\end{array}$ & $\begin{array}{c}20.2 \pm 2.4 \\
(18.8)\end{array}$ & $\begin{array}{l}23.2 \pm 2.1 \\
(23.6)\end{array}$ & $\begin{array}{c}23.3 \pm 1.9 \\
(25.0)\end{array}$ \\
\hline Longest event $\mathrm{s}$ & $\begin{array}{c}52.2 \pm 7.9 \\
(42.0)\end{array}$ & $\begin{array}{c}46.9 \pm 8.1 \\
(36.5)\end{array}$ & $\begin{array}{c}63.5 \pm 6.9 \\
(63.5)\end{array}$ & $\begin{array}{c}68.4 \pm 11.0 \\
(66.5)\end{array}$ \\
\hline Mean nadir $\mathrm{Sa}_{\mathrm{a}} \mathrm{O}_{2} \%$ & $\begin{array}{r}86 \pm 2 \\
(88)\end{array}$ & $\begin{array}{r}86 \pm 2 \\
(87)\end{array}$ & $\begin{array}{r}96 \pm 2 \\
(87)\end{array}$ & $\begin{array}{r}84 \pm 2 \\
(88)\end{array}$ \\
\hline Worst $\mathrm{Sa}_{\mathrm{a}, \mathrm{O}_{2}} \quad \%$ & $\begin{array}{r}77 \pm 3 \\
(82)\end{array}$ & $\begin{array}{r}79 \pm 2 \\
(80)\end{array}$ & $\begin{array}{c}73 \pm 2 \\
(75)\end{array}$ & $\begin{array}{r}73 \pm 2 \\
(74)\end{array}$ \\
\hline Total sleep time min & & & $\begin{array}{r}336 \pm 5 \\
(334)\end{array}$ & $\begin{array}{r}320 \pm 6 \\
(311)\end{array}$ \\
\hline Stage $1 \%$ TIB & $\begin{array}{r}14 \pm 2 \\
(14)\end{array}$ & $\begin{array}{r}15 \pm 2 \\
(10)\end{array}$ & $\begin{array}{r}14 \pm 2 \\
(13)\end{array}$ & $\begin{array}{r}14 \pm 2 \\
(13)\end{array}$ \\
\hline Stage $2 \%$ TIB & $\begin{array}{r}52 \pm 5 \\
(55)\end{array}$ & $\begin{array}{r}53 \pm 5 \\
(52)\end{array}$ & $\begin{array}{r}48 \pm 4 \\
(47)\end{array}$ & $\begin{array}{r}52 \pm 3 \\
(47)\end{array}$ \\
\hline Slow-wave \% TIB & $\begin{array}{r}22 \pm 6 \\
(15)\end{array}$ & $\begin{array}{c}21 \pm 6 \\
(11)\end{array}$ & $\begin{array}{r}16 \pm 4 \\
(14)\end{array}$ & $\begin{array}{r}13 \pm 3 \\
(10)\end{array}$ \\
\hline REM \% TIB & $\begin{array}{l}6 \pm 2 \\
(4)\end{array}$ & $\begin{array}{l}4 \pm 2 \\
(0)\end{array}$ & $\begin{array}{r}11 \pm 2 \\
(10)\end{array}$ & $\begin{array}{l}8 \pm 1 \\
(8)\end{array}$ \\
\hline $\begin{array}{l}\text { Total arousal index } \\
\text { events } \cdot \mathrm{h}^{-1}\end{array}$ & $\begin{array}{c}37.4 \pm 5.3 \\
(35.0)\end{array}$ & $\begin{array}{c}37.5 \pm 5.7 \\
(31.8)\end{array}$ & $\begin{array}{c}42.6 \pm 5.3 \\
(46.3)\end{array}$ & $\begin{array}{l}49.3 \pm 6.0^{*} \\
(52.9)\end{array}$ \\
\hline
\end{tabular}

Values are presented as mean \pm SEM, and median in parenthesis. CPAP: continuous positive airway pressure; AHI: apnoea/ hypopnoea index; AI: apnoea index; $\mathrm{Sa}_{\mathrm{a}} \mathrm{O}_{2}$ : arterial oxygen saturation TIB: time in bed; REM: rapid eye movement sleep. *: $\mathrm{p}=0.02$, control $v s$ alcohol (for all other values $\mathrm{p}>0.05$ ). 
a) Untreated
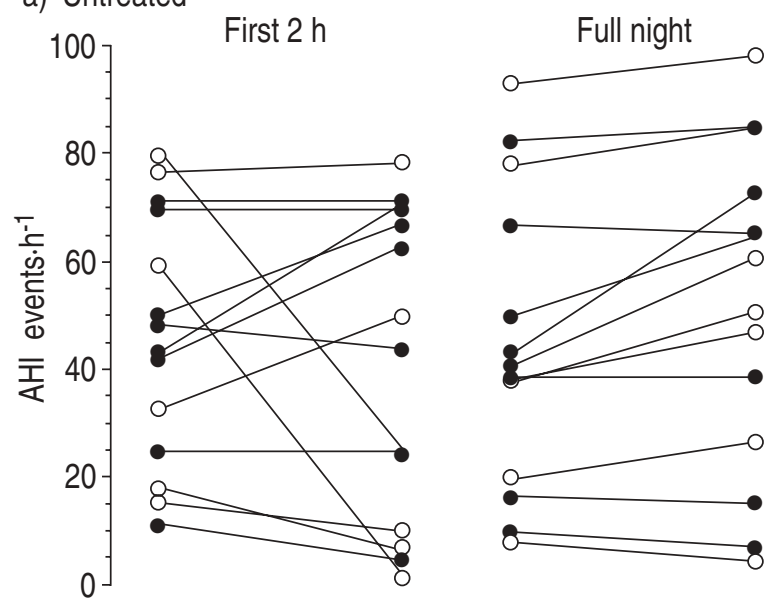

b) CPAP

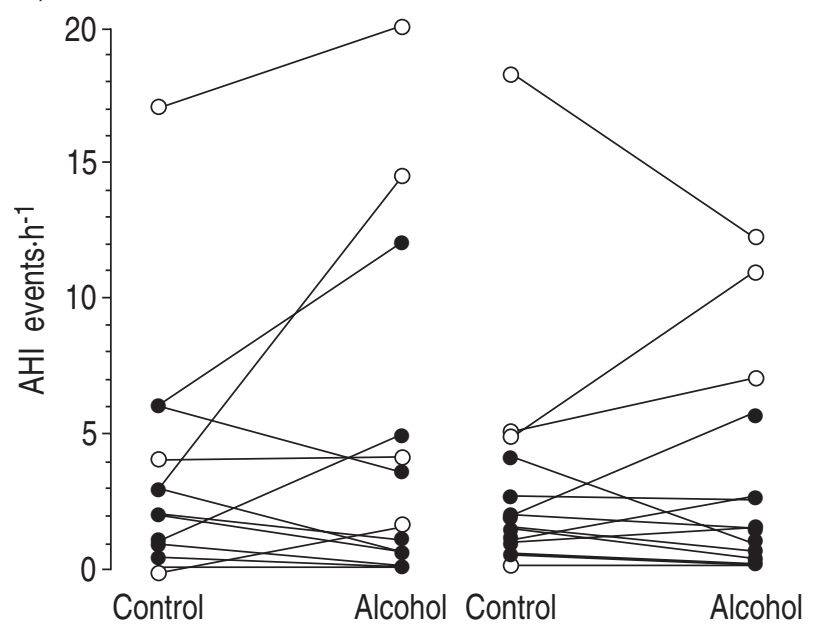

Fig. 1. - Apnoea/hypopnoea index (AHI) for the first $2 \mathrm{~h}$ and full night without (Control) and with alcohol. a) untreated; b) on AutoSet ${ }^{\mathrm{TM}}$ nasal continuous positive airway pressure (CPAP). $\mathrm{O}$ : subjects with alcohol night followed by control night; $\bullet$ : subjects with control night followed by alcohol night.

finding (control $11 \pm 2 \% v s$ alcohol $8 \pm 1 \%$ (mean \pm SEM), $\mathrm{p}=0.06$ ). Nine of 14 subjects had no REM sleep in the first $2 \mathrm{~h}$ with alcohol versus 3 of 14 subjects without alcohol. There were no important or significant changes in the percentage of time awake or in other sleep stages, or in AI.

\section{Effect of CPAP on sleep and breathing}

Results are summarized in figure 1 and tables 1 and 2. As expected, CPAP produced 10:1 to $15: 1$ reductions in $\mathrm{AI}$ and $\mathrm{AHI}(\mathrm{p}<0.001)$, and $4: 1$ to $6: 1$ reductions in the arousal index $(\mathrm{p}<0.001)$. For those apnoeas and hypopnoeas that did occur, the mean nadir saturation was higher $(\mathrm{p}<0.001)$ and event duration was shorter $(\mathrm{p}<$ 0.001 ). There was a highly significant increase in the percentages of both slow-wave sleep $(\mathrm{p}<0.001)$ and REM sleep $(\mathrm{p}<0.004)$.

\section{Effect of alcohol on sleep and breathing with CPAP}

Results are summarized in figure 1 and in table 2. During the first $2 \mathrm{~h}$, there was approximately $25 \%$ increase
Table 2. - Respiratory, sleep stage, and arousal results for the first $2 \mathrm{~h}$ and for the whole diagnostic night without (Control) and with alcohol, using AutoSet ${ }^{\mathrm{TM}}$ nasal CPAP

\begin{tabular}{|c|c|c|c|c|}
\hline & \multicolumn{2}{|c|}{ First $2 \mathrm{~h}$} & \multicolumn{2}{|c|}{ Whole night } \\
\hline & Control & Alcohol & Control & Alcohol \\
\hline AHI events $\cdot h^{-1}$ & $\begin{array}{l}3.3 \pm 1.2 \\
(2.0)\end{array}$ & $\begin{array}{l}4.5 \pm 1.7 \\
(1.3)\end{array}$ & $\begin{array}{c}3.3 \pm 1.2 \\
(1.8)\end{array}$ & $\begin{array}{l}3.1 \pm 1.1 \\
(1.3)\end{array}$ \\
\hline AI events $\cdot h^{-1}$ & $\begin{array}{c}1.5 \pm 0.4 \\
(1.0)\end{array}$ & $\begin{array}{c}2.9 \pm 1.2 \\
(1.3)\end{array}$ & $\begin{array}{l}1.5 \pm 0.4 \\
(1.4)\end{array}$ & $\begin{array}{c}1.8 \pm 0.7 \\
(0.8)\end{array}$ \\
\hline Event duration $\mathrm{s}$ & $\begin{array}{l}16.2 \pm 2.7 \\
(15.2)\end{array}$ & $\begin{array}{c}11.6 \pm 2.7 \\
(11.4)\end{array}$ & $\begin{array}{c}15.6 \pm 0.7 \\
(14.9)\end{array}$ & $\begin{array}{c}13.3 \pm 2.0 \\
(14.1)\end{array}$ \\
\hline Longest event $\mathrm{s}$ & $\begin{array}{l}52.2 \pm 7.9 \\
(42.0)\end{array}$ & $\begin{array}{c}46.9 \pm 8.1 \\
(36.5)\end{array}$ & $\begin{array}{c}63.5 \pm 6.9 \\
(63.5)\end{array}$ & $\begin{array}{c}68.4 \pm 11.0 \\
(66.5)\end{array}$ \\
\hline $\begin{array}{l}\text { Mean nadir } \\
\text { saturation } \%\end{array}$ & $\begin{array}{r}93 \pm 1 \\
(93)\end{array}$ & $\begin{array}{r}93 \pm 1 \\
(93)\end{array}$ & $\begin{array}{r}92 \pm 1 \\
(93)\end{array}$ & $\begin{array}{r}92 \pm 1 \\
(92)\end{array}$ \\
\hline Worst saturation \% & $\begin{array}{r}90 \pm 1 \\
(91)\end{array}$ & $\begin{array}{r}91 \pm 2 \\
(90)\end{array}$ & $\begin{array}{r}88 \pm 2 \\
(89)\end{array}$ & $\begin{array}{r}89 \pm 2 \\
(88)\end{array}$ \\
\hline $\begin{array}{l}\text { Total sleep time } \\
\text { min }\end{array}$ & & & $\begin{array}{c}358 \pm 3 \\
(360)\end{array}$ & $\begin{array}{r}360 \pm 2 \\
(361)\end{array}$ \\
\hline Stage $1 \%$ TIB & $\begin{array}{c}10 \pm 2 \\
(7)\end{array}$ & $\begin{array}{c}7 \pm 1 \\
(6)\end{array}$ & $\begin{array}{l}8 \pm 1 \\
(7)\end{array}$ & $\begin{array}{l}7 \pm 1 \\
(6)\end{array}$ \\
\hline Stage $2 \%$ TIB & $\begin{array}{r}29 \pm 4 \\
(26)\end{array}$ & $\begin{array}{r}26 \pm 4 \\
(25)\end{array}$ & $\begin{array}{r}35 \pm 3 \\
(36)\end{array}$ & $\begin{array}{r}30 \pm 3 \\
(30)\end{array}$ \\
\hline Slow-wave \% TIB & $\begin{array}{r}39 \pm 6 \\
(33)\end{array}$ & $\begin{array}{c}51 \pm 4 * \\
(45)\end{array}$ & $\begin{array}{r}32 \pm 3 \\
(33)\end{array}$ & $\begin{array}{r}36 \pm 4 \\
(37)\end{array}$ \\
\hline REM \% TIB & $\begin{array}{r}15 \pm 4 \\
(11)\end{array}$ & $\begin{array}{c}8 \pm 2 \\
(9)\end{array}$ & $\begin{array}{r}15 \pm 2 \\
(14)\end{array}$ & $\begin{array}{r}17 \pm 2 \\
(19)\end{array}$ \\
\hline $\begin{array}{l}\text { Total arousal index } \\
\text { events } \mathrm{h}^{-1}\end{array}$ & $\begin{array}{l}7.4 \pm 2.6 \\
(4.5)\end{array}$ & $\begin{array}{l}7.6 \pm 0.9 \\
(7.3)\end{array}$ & $\begin{array}{r}10.6 \pm 2.9 \\
(7.3)\end{array}$ & $\begin{array}{c}8.1 \pm 1.2 \\
(7.2)\end{array}$ \\
\hline
\end{tabular}

Values are presented as mean $\pm \mathrm{SEM}$, and median in parenthesis. For definitions see legend to table $1 . *: \mathrm{p}=0.004$, control $v s$ alcohol (for all other values $\mathrm{p}>0.05$ ).

in the percentage of time in slow-wave sleep. Otherwise, there was no change in any relevant parameter with alcohol during CPAP therapy. In particular, there was no decrease in the percentage of REM sleep. This was significantly different to the finding without CPAP (table 1), where many subjects had decreased REM sleep in the first $2 \mathrm{~h}$ after alcohol. There was a significant alcoholby-CPAP interaction $(\mathrm{p}=0.015)$; in other words, the effect of alcohol on REM sleep was influenced by CPAP. There was no such interaction for the other sleep or breathing parameters studied.

\section{Effect of alcohol on pressure requirement for CPAP}

Results are shown in table 3 and in figures 2 and 3. Overall, there was no significant effect of alcohol on recommended pressure (95th percentile) used for CPAP.

Table 3. - Median and 95th percentile (recommended) pressure for AutoSet ${ }^{\mathrm{TM}}$ nasal CPAP use for the first $2 \mathrm{~h}$ and for the whole diagnostic night without (Control) and with alcohol

\begin{tabular}{ccccc}
\hline & \multicolumn{2}{c}{ First $2 \mathrm{~h}$} & \multicolumn{2}{c}{ Whole night } \\
& Control & Alcohol & Control & Alcohol \\
\hline Median pressure & $8.6 \pm 0.5$ & $8.9 \pm 0.7$ & $8.8 \pm 0.5$ & $8.9 \pm 0.5$ \\
$\mathrm{CmH}_{2} \mathrm{O}$ & $(8.4)$ & $(8.1)$ & $(8.6)$ & $(9.1)$ \\
Recommended & $10.9 \pm 0.6$ & $11.1 \pm 0.8$ & $11.9 \pm 0.9$ & $12.5 \pm 0.9$ \\
pressure $\mathrm{cmH}_{2} \mathrm{O}$ & $(10.3)$ & $(10.8)$ & $(11.6)$ & $(12.0)$ \\
\hline
\end{tabular}

Values are presented as mean $\pm \mathrm{SEM}$, and median in parenthesis. CPAP: continuous positive airway pressure. 


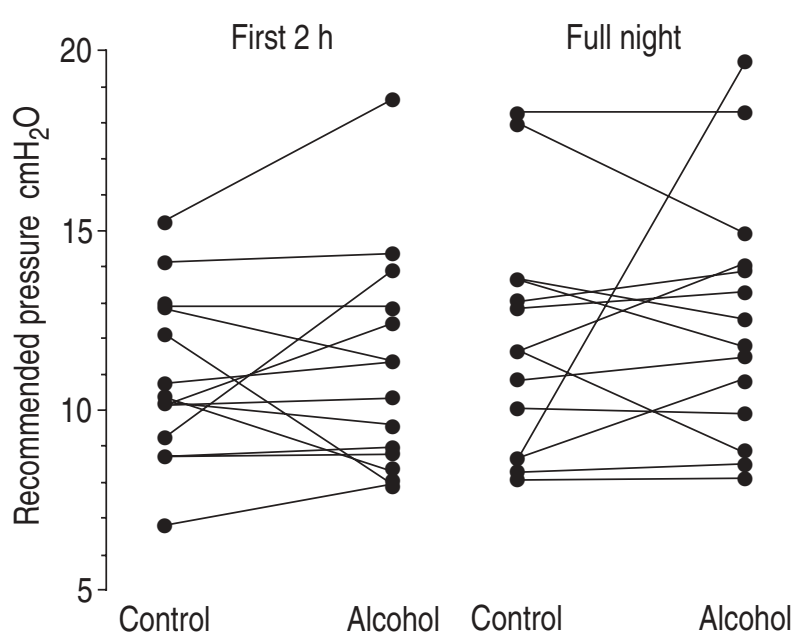

Fig. 2. - AutoSet ${ }^{\mathrm{TM}}$ recommended fixed pressure for nasal continuous positive airway pressure (CPAP) for the first $2 \mathrm{~h}$ and full night without (Control) and with alcohol.

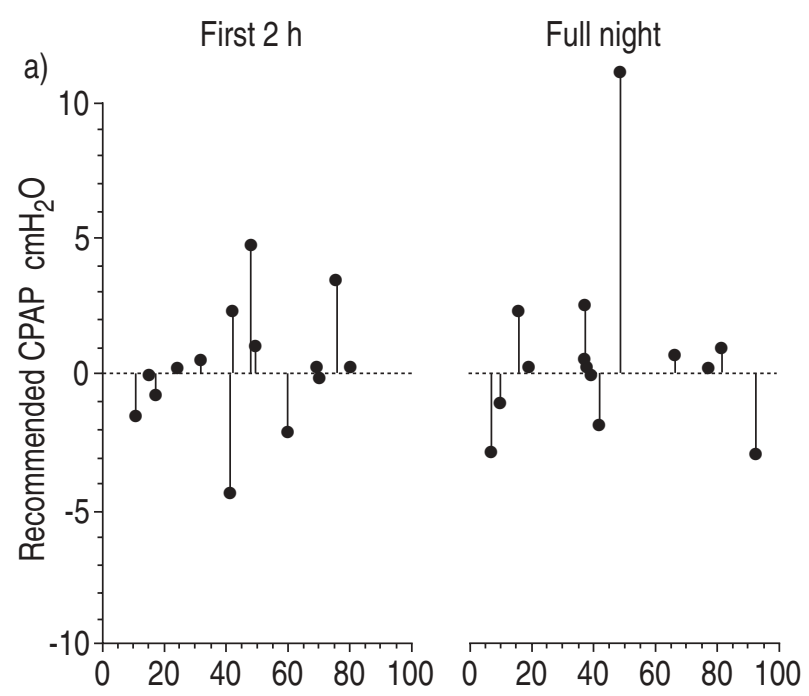

b)

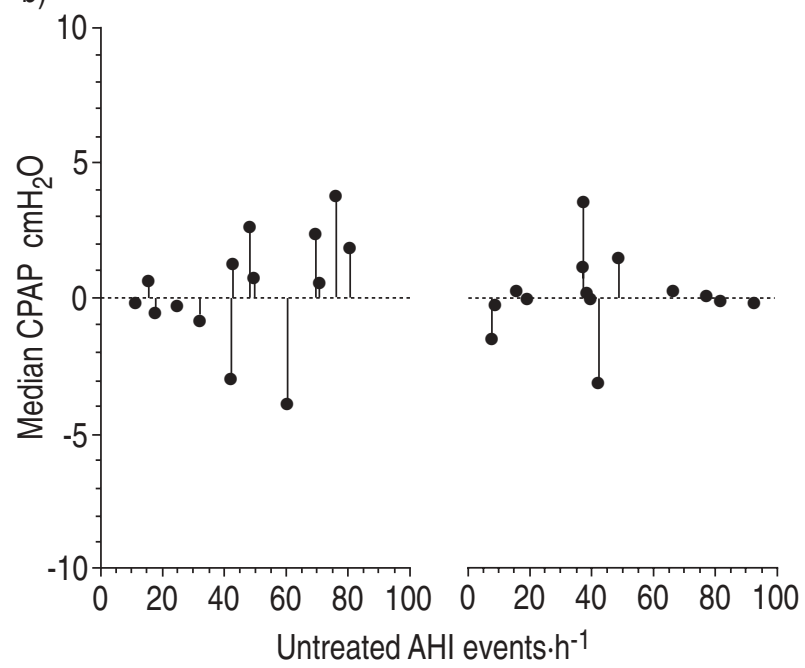

Fig. 3. - a) Change in recommended pressure for nasal continuous positive airway pressure (CPAP) use with alcohol, for first $2 \mathrm{~h}$ of study and for full night, plotted against untreated alcohol-free apnoea/hypopnoea index (AHI) for individual subjects. b) Change in median pressure.
In 9 of the 14 subjects, alcohol caused less than a 2 $\mathrm{cmH}_{2} \mathrm{O}$ change in the recommended pressure, and in all but one subject the change was less than $3.5 \mathrm{cmH}_{2} \mathrm{O}$ (fig. 2 ). In the one remaining subject, there was a marked increase in peak pressure on the alcohol night. However, this was associated with severe, persistent mouth breathing, interfering with autotitration, and the increase in pressure was, therefore, probably in error. This subject did not mouth breathe on the alcohol-free nights, or without CPAP. Similarly, there were no consistent changes in pressure requirement when the first $2 \mathrm{~h}$ were examined. There was no correlation between the change in recommended (fig. 3a) and median (fig. 3b) pressure with alcohol and the untreated control AHI.

There was no effect of order of presentation of alcohol and control nights on the apnoea/hypopnoea index without CPAP (control first: 46.1 events $\cdot \mathrm{h}^{-1}$ vs 53.0 with alcohol; alcohol first: 48.2 events $\cdot \mathrm{h}^{-1}$ vs 42.1 control; alcohol-by-order interaction NS). Similarly, order did not affect the $\mathrm{Sa}_{\mathrm{a}} \mathrm{O}_{2}$ measurements.

\section{Discussion}

\section{Alcohol without CPAP}

This study has demonstrated that moderate amounts of alcohol (roughly equivalent to that in half a bottle of wine) do not necessarily have a deleterious effect on breathing and oxygenation in mild-to-severe untreated obstructive sleep apnoea: in this patient group, 1.5 $\mathrm{mL} \cdot \mathrm{kg}^{-1} \mathrm{BW}$ vodka, giving a mean blood alcohol level of $0.45 \mathrm{mg} \cdot \mathrm{mL}^{-1} 1 \mathrm{~h}$ later at sleep onset, was not on average associated with any marked change in breathing during sleep. The above results applied equally to the whole night and to the first $2 \mathrm{~h}$.

The present results conflict with those of SCRIMA et al. [8] and Collop [13], who found increases in the apnoea/ hypopnoea index and more severe reduction in $\mathrm{Sa}, \mathrm{O}_{2}$ at comparable alcohol doses. The larger changes seen in the studies by Guilleminault and Rosekind [14], Issa and Sullivan [1], and VAlET et al. [15], are very likely to be attributable to much higher alcohol doses, and in the case of Issa and SulLivan [1], where results were most striking, possibly to vasoactive substances present in beer, wine, etc., as well as co-existing severe lung disease in some subjects.

Without CPAP, alcohol produced a modest increase in the arousal index. There was also the expected decrease in the percentage of REM sleep although this was not significant, comparable to that seen by GuILLEMINAULT and ROSEKIND [14], with many subjects having no REM sleep at all during the first $2 \mathrm{~h}$ of the study, when the alcohol concentration would have been highest. It is, therefore, very possible that the failure of $0.5 \mathrm{~g} \cdot \mathrm{kg}^{-1} \mathrm{BW}$ of alcohol to impair breathing and oxygenation during sleep was due to the fact that the alcohol inhibited REM sleep, when sleep apnoea would be expected to be worse; and/or that the alcohol was largely metabolized prior to the delayed onset of REM sleep. However, the suppression of REM sleep was not universal and did not last all night.

In this study, control and alcohol nights were in random order, one night apart. TAASAN et al. [11] reported 
a carry-over effect of alcohol to the subsequent night, so that a control night following an alcohol night showed sleep-disordered breathing on both nights (we speculate that this was probably due to REM rebound on the control night). No such order effect was seen in the present study, perhaps because the dose of alcohol was smaller.

\section{Effects of AutoSet ${ }^{\mathrm{TM}}$ nasal CPAP}

AutoSet ${ }^{\mathrm{TM}}$ has previously been shown to produce excellent reductions in AI, AHI, arousal index, and REM and slow-wave rebound [17-19]. Similar results were seen in the present study, both with and without alcohol. Alcohol caused a modest increase in the arousal index without CPAP, and a modest increase in the percentage of slow-wave sleep with CPAP.

\section{Alcohol with CPAP}

The expected decrease in the percentage of REM sleep due to alcohol was not seen during CPAP treatment. This was presumably because the alcohol effect was swamped by the REM rebound produced by the relief of upper airway obstruction; if (and only if) this were the case, the alcohol effect on REM would be expected to reappear in a subject who was on long-term stable CPAP therapy. Despite the larger amount of REM, there was no deterioration in the AHI or in $\mathrm{Sa}_{\mathrm{a}} \mathrm{O}_{2}$ with alcohol on CPAP. With CPAP, alcohol did not so clearly increase the arousal index (perhaps because of the slow-wave rebound caused by the CPAP), but the interaction between the effects of CPAP and alcohol on the arousal index was not statistically significant.

\section{Pressure requirement}

There was no change in the pressure required for CPAP in order to prevent apnoeas, snoring, and silent inspiratory airflow limitation. This was equally true of subjects with mild and severe OSAS, and was also true for the first $2 \mathrm{~h}$, when the blood alcohol level would have been highest. This result conflicts with the findings of MITLER et al. [12], who found a small increase in the pressure required to prevent snoring in nonapnoeic snorers, but is compatible with the results of BERRY et al. [16], who found that there was no change in the AHI or $\mathrm{Sa}_{\mathrm{a}} \mathrm{O}_{2}$ with alcohol in subjects who were already on adequate CPAP. One possible explanation is that in patients with frank OSAS, as opposed to snoring, the upper airway is already almost totally floppy during sleep, and the existing pressure used for CPAP provides nearly all of the inspiratory support. Consequently, reducing the dilator muscle tone removes little support, and no further increase in pressure is required for CPAP. We would speculate, however, that beverages, such as beer or wine, could act in an additional manner, by producing nasal congestion, and thereby requiring higher pressures for CPAP. Therefore, it is not possible to extrapolate the present results to other beverages.

In the present study, an automatic titrating device was used. A potential advantage is that this eliminates the possibility of unintended bias that could occur by determining the titration pressure manually. Laboratories differ as to how they perform titration, and there is no consensus as to the correct endpoint. Most laboratories aim to eliminate obstructive apnoeas and hypopnoeas, but their criteria for doing so differ. Some stop when there are no further arterial oxygen desaturations, some when there is no further snoring, and some, using a pneumotachometer to measure the shape of the inspiratory flow-time curve, also aim to minimize silent inspiratory airflow limitation. The latter has been shown [21] to indicate the presence of high upper airway resistance and large oesophageal pressure swings, which can lead to repetitive arousals in the absence of apnoeas and hypopnoeas [22]. The AutoSet ${ }^{\mathrm{TM}}$ system detects and quantifies the degree of flattening of the inspiratory flow-time curve and sets the pressure accordingly $[17,18]$. Thus, it is essentially acting like a technician who titrates by normalizing the degree of silent inspiratory airflow limitation, but with the advantage that an objective, rather than subjective, measure of the degree of flattening is being used. In general, the pressure required to eliminate flow limitation is probably slightly higher than that required to eliminate apnoeas and snoring alone. Hence, the present study does not exclude the possibility that subjects titrated solely on CPAP using apnoea and snore criteria might have slightly inadequate pressure with alcohol.

In conclusion, a single $0.5 \mathrm{~g} \cdot \mathrm{kg}^{-1} \mathrm{BW}$ dose of alcohol, in the form of vodka, does not appear to systematically worsen breathing or arterial oxygen saturation during sleep in subjects with uncomplicated sleep apnoea syndrome. The pressure required for continuous positive airway pressure use in order to prevent silent inspiratory airflow limitation remains adequate after this dose of alcohol. These results cannot be generalized to patients with concurrent heart, lung or liver disease, higher doses of alcohol, chronic ingestion of alcohol, or ingestion of alcohol in vasoactive beverages. Finally, there is the possibility that occasional subjects may have an atypical or more extreme response to alcohol than that seen in this study.

\footnotetext{
Acknowledgement: The authors thank H. Baumann, A. Brondics, G. Dölle, A. Farhat, O. Lotz and F. Mihaltan
} for their assistance with the data collection.

\section{References}

1. Issa FG, Sullivan CE. Alcohol, snoring and sleep apnea. J Neurol Neurosurg Psychiatr 1982; 45: 353-359.

2. Sullivan CE, Berthon-Jones M, Eves L. Reversal of obstructive sleep apnea by continuous positive airway pressure applied through the nares. Lancet 1981; 1: 862-865.

3. Bonora M, Shields GI, Knuth SL, Bartlett D, St. John WM. Selective depression by ethanol of upper airway respiratory motor activity in cats. Am Rev Respir Dis 1984; 130: 156-161.

4. Krol RC, Knuth SL, Bartlett D. Selective reduction of genioglossal muscle activity by alcohol in normal human subjects. Am Rev Respir Dis 1984; 129: 247-250.

5. Robinson RW, White DP, Zwillich CW. Moderate alcohol ingestion increases upper airway resistance in normal subjects. Am Rev Respir Dis 1985; 132: 1238-1241. 
6. St. John WM, Bartlett D, Knuth KV, Knuth SL, Daubenspeck JA. Differential depression of hypoglossal nerve activity by alcohol. Am Rev Respir Dis 1986; 133: 46-48.

7. Berry RB, Bonnet MH, Light RW. Effect of ethanol on the arousal response to airway occlusion during sleep in normal subjects. Am Rev Respir Dis 1992; 145: 445-452.

8. Scrima L, Broudy M, Nay KN, Cohn MA. Increased severity of obstructive sleep apnea after bedtime alcohol ingestion: diagnostic potential and proposed mechanism of action. Sleep 1982; 5: 318-328.

9. Scrima L, Hartman PG, Hiller FC. Effect of three alcohol doses on breathing during sleep in 30-49 year old nonobese snorers and nonsnorers. Alcohol Clin Exp Res 1989; 13: 420-427.

10. Block AJ, Hellard DW, Slayton PC. Effect of alcohol ingestion on breathing and oxygenation during sleep. $\mathrm{Am}$ J Med 1986; 80: 595-600.

11. Taasan VC, Block AJ, Boysen PG, Wynne JW. Alcohol increases sleep apnea and oxygen desaturation in asymptomatic men. Am J Med 1981; 71: 240-245.

12. Mitler MM, Dawson A, Henriksen SJ, Sobers M, Bloom FE. Bedtime ethanol increases resistance of upper airways and produces sleep apneas in asymptomatic snorers. Alcohol Clin Exp Res 1988; 12: 801-805.

13. Collop NA. Medroxyprogesterone acetate and ethanolinduced exacerbation of obstructive sleep apnea. Chest 1994; 106: 792-793.

14. Guilleminault C, Rosekind M. The arousal threshold: sleep deprivation, sleep fragmentation, and obstructive sleep apnea syndrome. Bull Eur Physiopathol Respir 1981; 17: 341-349.
15. Valet A, Ockenga A, Mayer J, Peter HJ, Pick-Kober $\mathrm{KH}$, vonWichert P. Unverträglichkeit von Alkohol bei Patienten mit Schlafapnoe-Syndrom. Med Klin 1986; 13: 441-444.

16. Berry RB, Desa MM, Light RW. Effect of ethanol on the efficacy of nasal continuous positive airway pressure as a treatment for obstructive sleep apnea. Chest 1991; 99: 339-343.

17. Berthon-Jones M. Feasibility of a self-setting CPAP machine. Sleep 1993; 16: 120-123.

18. Berthon-Jones M, Lawrence S, Sullivan CE. A self-setting device for OSA. Sleep 1996; (in press).

19. Teschler H, Thompson AB, Berthon-Jones M, Henkel A, Henry J, Konietzko N. Automated continuous positive airway pressure titration for obstructive sleep apnea syndrome. Am J Respir Crit Care Med 1996; 154: (in press).

20. Rechtschaffen A, Kales AA. Manual of standardized terminology, techniques and scoring system for the sleep stages of human subjects. National Institute of Health, Publication No. 204, US Government Printing Office, Washington, DC, 1968.

21. Condos R, Norman RG, Krishnasamy I, Peduzzi N, Goldring RM, Rapoport DM. Flow limitation as a noninvasive assessment of residual upper airway resistance during continuous positive airway pressure therapy of obstructive sleep apnea. Am J Respir Crit Care Med 1994; 150: 475-480.

22. Guilleminault C, Stoohs R, Clerk A, Cetet M, Maistros P. A cause of excessive daytime sleepiness: the upper airway resistance syndrome. Chest 1993; 104: 781-787. 